\title{
Effect of long-term fertilization on bacterial community in a sandy loam soil and its relation to organic carbon accumulation
}

\author{
Huanjun Zhang ${ }^{1}$, Xixi Wang ${ }^{1}$, Yi Li ${ }^{1, *}$, Weixin Ding ${ }^{2}$ \\ ${ }^{1}$ Key Laboratory of Integrated Regulation and Resource Development on Shallow Lakes, Ministry of Education, College of Environment, \\ Hohai University, Nanjing 210098, China \\ ${ }^{2}$ State Key Laboratory of Soil and Sustainable Agriculture, Institute of Soil Science, Chinese Academy of Sciences, Nanjing 210008 , \\ China
}

\begin{abstract}
Fertilization can affect the transformation of soil organic carbon (SOC) and soil microbial community composition. However, thus far, how SOC accumulation in association with bacterial community is still unclear. We collected arable soils (aquic inceptisol) from a long-term fertilization experiment (20 years) including compost (CM), inorganic nitrogen + phosphorus + potassium (NPK), half compost $\mathrm{N}$ plus half inorganic fertilizer $\mathrm{N}(\mathrm{HCM}), \mathrm{NP}, \mathrm{NK}, \mathrm{PK}$, and untreated (Control). We investigated the relationship between the SOC accumulation rate and bacterial community composition measured by high-throughput sequencing. The highest SOC accumulation rate was observed in the compost treatments. Furthermore, compost and balanced NPK treatments increased soil carbohydrate content significantly $(\mathrm{P}<$ 0.05), while no such enhancement was observed following NK and PK application. Compared with the Control, fertilization substantially reduced the effective diffusion coefficient of oxygen in soil. Meanwhile, fertilization lowered the relative abundance (RA) of Bacteroidetes but increased the RA of Proteobacteria. Compost application increased the RA of Firmicutes, while inorganic fertilizers reduced it. The RA of Proteobacteria and Firmicutes were significantly and positively correlated with the SOC and carbohydrate content and the SOC accumulation rate $(\mathrm{P}<0.05)$. SOC accumulation was also accompanied with the reduction in the effective diffusion coefficient of oxygen in soil. Our results indicated that poor aeration may induce a shift in the microbial community composition and a transition from aerobic to anaerobic degradation of SOC, thereby favoring SOC accumulation.
\end{abstract}

Keywords: Long-term fertilization; High-throughput sequencing; Microbial community; Organic C accumulation.

\section{Introduction}

Bacteria play significant roles in biogeochemical cycles in agricultural ecosystems, such as decomposition and conversion of soil organic carbon (C) and accompanied release of nutrients for plant growth [1]. Soil microbial communities are greatly impacted by soil chemical and physical properties such as nutrient level, $\mathrm{pH}$, quantity and quality of organic $\mathrm{C}$, water content, and oxygen level. In agricultural ecosystems, fertilizer management practices can affect nearly all these edaphic factors, leading to shifts in the microbial community composition. Although, in recent years, the response of soil microbial community to organic and inorganic fertilization have been extensively investigated [2], the information about the relation between alterations in bacterial community composition and soil organic carbon (SOC) sequstration as affected by different soil fertilization treatments is still limited.
Organic fertilization may positively influence microbial diversity, biomass, activity, and help maintain or increase the SOC content, while inorganic fertilization is less effective relative to organic fertilization [3]. Several researches have revealed that soil bacterial community is highly sensitive to organic and inorganic fertilizations, but such responses differ among phyla [1]. Nonetheless, some studies also revealed that current application of inorganic fertilizers has a major deleterious impact on the inherent soil microbial community, such as decreases of microbial biomass [4] and microbial diversity [5]. For instance, Jangid et al. [1] revealed that inorganic fertilization in croplands and pastures significantly reduced the microbial diversity and altered the composition of bacterial phyla, involving Acidobacteria, Bacteroidetes, Firmicutes, Betaproteobacteria and Gammaproteobacteria. The overloading of nitrogen (N) fertilizer reduced microbial biodiversity and enhanced nitrification [6]. However, it was found that variations in the soil bacterial community structure resulting from

\footnotetext{
* Corresponding author: envly@hhu.edu.cn
} 
inorganic fertilization could be resumed by organic fertilization [2].

Fertilization-related alterations in microbial community structure can be related to variations in the soil environmental conditions. However, the response of diverse bacterial communities to the varying environment in arable soils has not been clearly stated. Here, we evaluated variations in the bacterial community composition in a sandy loam soil as influenced by various long-term organic and inorganic fertilizations. This study aimed to elucidate the key factors regulating the shifts in the bacterial community composition and to understand the relationships between SOC accumulation and bacterial community composition. The hypothesis was that the bacterial community composition corresponds to variations in soil properties, which will in turn change the SOC accumulation rate.

\section{Materials and methods}

\subsection{Field experiments and soil property analysis}

Fengqiu Agro-ecological Experimental Station was located in Henan province, China $\left(35^{\circ} 00^{\prime} \mathrm{N}, 114^{\circ} 24^{\prime} \mathrm{E}\right)$. A long-term fertilization experiment was established in the Agro-ecological Experimental Station in September 1989. The soil was originated from alluvial sediments of the Yellow River with a sandy loam texture. The mean annual temperature was $13.9{ }^{\circ} \mathrm{C}$ and the mean annual precipitation was $615 \mathrm{~mm}$, representing a semi-arid, subhumid monsoon climate in this region. In 1989, the soil $(0-20 \mathrm{~cm})$ parameters were: organic carbon, $4.48 \mathrm{~g} \cdot \mathrm{kg}^{-1}$; total nitrogen, $0.43 \mathrm{~g} \cdot \mathrm{kg}^{-1}$; total phosphorus, $0.50 \mathrm{~g} \cdot \mathrm{kg}^{-1}$; and total potassium, $18.60 \mathrm{~g} \cdot \mathrm{kg}^{-1} ; \mathrm{pH}, 8.65$.

In the long-term experiemnt, seven fertilization treatments with four replicates were included: (1) only compost $(\mathrm{CM}),(2)$ half compost nitrogen plus half inorganic nitrogen fertilizer (HCM), (3) combined inorganic nitrogen + phosphorus + potassium fertilizers (NPK), (4) combined inorganic nitrogen + phosphorus fertilizers (NP), (5) combined inorganic nitrogen + potassium fertilizers (NK), (6) combined inorganic phosphorus + potassium fertilizers (PK), and (7) no fertilization (Control). A total of 28 plots were analyzed. Table 1 presents the details of $\mathrm{N}, \mathrm{P}$, and $\mathrm{K}$ application rates for each treatment. Each plot had a size of $9.5 \mathrm{~m}$ in length and $5 \mathrm{~m}$ in width. The experiment design was a randomized block for all the plots. The compost was made by fermenting cakes of soybean and cottonseed, and wheat straw for 2 months and had $422 \mathrm{~g} \mathrm{C} \cdot \mathrm{kg}^{-1}$. The cropping system was a rotation of summer maize (Zea mays cv. Zhengdan 958) and winter wheat (Triticum aestiv ${ }^{l}$ um cv. Xinmai 19). Basal fertilizers were evenly applied in the respective plots before tillage which was conducted by hoes to a soil depth of $20 \mathrm{~cm}$ every season. Then the maize and wheat were sowed after tillage in early June and early October, respectively. Moreover, the soil surface was treated with supplemental $\mathrm{N}$ fertilizer in HCM, NPK, NP and NK treatments in late July and in late February for maize and wheat, respectively, followed by irrigation or rainfall. All the plots applied same field management practices other than fertilization during the experiment. Detailed information regarding the experiment management has been reported by $\mathrm{Yu}$ et al. [7].

An auger with $2.5-\mathrm{cm}$-diameter was used to collect soil samples in each plot to a depth of $20 \mathrm{~cm}$ on 7 June 2009 . The soil cores were homogenized, stored at $4{ }^{\circ} \mathrm{C}$, and taken to the lab as soon as possible for further analysis. Fresh soil samples were gently ruptured along natural fissures and sieved to $<8 \mathrm{~mm}$, and then visible plant residues and organic debris were carefully eliminated by forceps. These fresh samples were utilized for molecular analyses. An air-dried subsample passing through a 2 $\mathrm{mm}$ sieve was prepared to measure soil properties.

A pH meter (DMP-2, Quark Ltd., Nanjing, China) was applied to determine soil $\mathrm{pH}$. The wet oxidation-redox titration method were performed to measure SOC content and the micro-Kjeldahl method were performed to measure total $\mathrm{N}$ content in soil. The soil carbohydrate content was determined following Puget et al. [8].

\subsection{Effective oxygen diffusion coefficient}

In each plot eight undisturbed soil core samples with volume of $100 \mathrm{~cm}^{3}$ were collected. The ceramic pressure plate method was employed at equilibrium matric potentials of $-1,-2,-10,-35,-60,-100,-330,-500$, $-1000,-2000,-5000$, and $-15000 \mathrm{hPa}$ to measure soil water retention curve.

The effective soil oxygen diffusion coefficient $\left(D, \mathrm{~m}^{2} \cdot \mathrm{s}^{-1}\right)$ was computed as follows [9]:

$$
D=1 / N^{2} \times\left[\left(D_{a 0} \times Q_{a}{ }^{p}\right)+\left(K H \times D_{w 0} \times Q_{w}{ }^{p}\right)\right]
$$

Table 1 Amount of nutrient inputs (N, P, and K) through organic or inorganic fertilization in each cropping season under different treatments

\begin{tabular}{|c|c|c|c|c|c|c|c|}
\hline \multirow{3}{*}{$\begin{array}{l}\text { Treat } \\
\text { ment }\end{array}$} & \multicolumn{6}{|c|}{ Basal fertilizer } & \multirow{3}{*}{$\begin{array}{c}\text { Supplem } \\
\text { entary } \\
\text { fertilizer } \\
\text { urea } \\
(\mathrm{kg} \\
\left.\mathrm{N} \cdot \mathrm{ha}^{-1}\right)\end{array}$} \\
\hline & \multicolumn{2}{|c|}{$\begin{array}{c}\mathrm{N}(\mathrm{kg} \\
\left.\mathrm{N} \cdot \mathrm{ha}^{-1}\right)\end{array}$} & \multicolumn{2}{|c|}{$\mathrm{P}\left(\mathrm{kg} \mathrm{P}_{2} \mathrm{O}_{5} \cdot \mathrm{ha}^{-1}\right)$} & \multicolumn{2}{|c|}{$\begin{array}{c}\mathrm{K}\left(\mathrm{kg} \mathrm{K}_{2} \mathrm{O} \mathrm{ha}^{-}\right. \\
\left.{ }^{1}\right)\end{array}$} & \\
\hline & $\begin{array}{l}\text { Com } \\
\text { post }\end{array}$ & $\begin{array}{l}\text { Ur } \\
\text { ea }\end{array}$ & $\begin{array}{l}\text { Com } \\
\text { post }\end{array}$ & $\begin{array}{c}\text { Calcium } \\
\text { superpho } \\
\text { sphate }\end{array}$ & $\begin{array}{l}\text { Com } \\
\text { post }\end{array}$ & $\begin{array}{c}\text { Potas } \\
\text { sium } \\
\text { sulfat } \\
\text { e }\end{array}$ & \\
\hline \multicolumn{8}{|c|}{ Maize } \\
\hline $\begin{array}{c}\text { Contr } \\
\text { ol }\end{array}$ & 0 & 0 & 0 & 0 & 0 & 0 & 0 \\
\hline HCM & 75 & 0 & 25.5 & 49.5 & 32.5 & 117.5 & 75 \\
\hline $\mathrm{CM}$ & 150 & 0 & 51 & 24 & 65 & 85 & 0 \\
\hline NPK & 0 & 60 & 0 & 75 & 0 & 150 & 90 \\
\hline NP & 0 & 60 & 0 & 75 & 0 & 0 & 90 \\
\hline NK & 0 & 60 & 0 & 0 & 0 & 150 & 90 \\
\hline PK & 0 & 0 & 0 & 75 & 0 & 150 & 0 \\
\hline \multicolumn{8}{|c|}{ Wheat } \\
\hline $\begin{array}{c}\text { Contr } \\
\text { ol }\end{array}$ & 0 & 0 & 0 & 0 & 0 & 0 & 0 \\
\hline $\mathrm{HCM}$ & 75 & 15 & 22.5 & 52.5 & 31.5 & 118.5 & 60 \\
\hline $\mathrm{CM}$ & 150 & 0 & 45 & 30 & 63 & 87 & 0 \\
\hline NPK & 0 & 0 & 0 & 75 & 0 & 150 & 60 \\
\hline NP & 0 & 0 & 0 & 75 & 0 & 0 & 60 \\
\hline NK & 0 & 0 & 0 & 0 & 0 & 150 & 60 \\
\hline $\mathrm{PK}$ & 0 & 0 & 0 & 75 & 0 & 150 & 0 \\
\hline
\end{tabular}

where $N$ is the soil porosity (\%) calculated by soil bulk density $(\rho)$ and particle density $\left(2.65 \mathrm{~g} \cdot \mathrm{cm}^{-3}\right) ; D_{a 0}$ is the free diffusion coefficient of oxygen in the air at $20^{\circ} \mathrm{C}$ 
$\left(1.8 \times 10^{-5} \mathrm{~m}^{2} \cdot \mathrm{s}^{-1}\right) ; K H$ is Henry's equilibrium constant at $20{ }^{\circ} \mathrm{C}(0.03) ; D_{w 0}$ is the free oxygen diffusion coefficient in the water at $20^{\circ} \mathrm{C}\left(2.2 \times 10^{-9} \mathrm{~m}^{2} \cdot \mathrm{s}^{-1}\right) ; Q_{a}$ is the ratio of soil porosity filled with air and $Q_{w}$ is the ratio of soil porosity filled with water, i.e., $Q_{a}+Q_{w}=1$; and $p$ is a power constant (3.4). The $Q_{w}$ was calculated by:

$$
Q_{w}=\rho \times \theta_{m} / N
$$

where $\theta_{m}$ is the water content of soil $\left(\mathrm{cm}^{3} \cdot \mathrm{g}^{-1}\right)$.

\subsection{Measurement of the specific mineralization rate}

To measure the specific $\mathrm{C}$ mineralization rate (SCMR), $10 \mathrm{~g}$ soil seieved to $<2 \mathrm{~mm}$ was put in a glass jar with volume of $150-\mathrm{mL}$. The moisture content of soil was regulated to $60 \%$ of WHC (water-holding capacity) for all soil samples during the incubation. The jars covered by ventilated film were placed in an incubator at $25^{\circ} \mathrm{C}$ and the deionized water was added once every two days to maintain soil moisture content the same as initial condtion during the incubation. The $\mathrm{CO}_{2}$ emission rate was measured on the $0.5,1,2,3,5,7,9,11,13,15,18$, $21,24,28$, and 32 days of the incubation. For measuring $\mathrm{CO}_{2}$ emissions, the jar was plugged with a rubber lid perforated by centered Perspex tubes. Then, an hermetic syringe was utilized to collect $1 \mathrm{~mL}$ headspace gas immediately and at $6 \mathrm{~h}$ after closure to dertermine the $\mathrm{CO}_{2}$ concentration by a gas chromatograph (Agilent 7890, Santa Clara, CA, USA). The $\mathrm{CO}_{2}$ emission rate representing organic $\mathrm{C}$ mineralization rate (CMR) was computed by assuming the $\mathrm{CO}_{2}$ concentration was linearly changed during the 6-h incubation in the airtight jar at temperature of $20^{\circ} \mathrm{C}$. The SCMR was calculated using the following equation [7]:

$\mathrm{SCMR}=\mathrm{CMR} / \mathrm{SOC}$ content.

\subsection{Soil DNA extraction}

Fresh soil samples of $0.5 \mathrm{~g}$ (on the oven-dried basis) was used to extract total DNA by a Fast DNA Spin Kit for Soil (MP Biomedicals, CA, USA) based on the manufacturers' protocols. The gel electrophoresis and NanoDrop spectrophotometer (NanoDrop Technologies, Wilmington, USA) were employed to measure the quality and concentration of the extracted DNA, respectively, and then the extracted DNA was subsequently preserved at $-20^{\circ} \mathrm{C}$.

\subsection{Illumina sequencing and data analysis}

The primers $802 \mathrm{R}$ (5'-TACNVGGGTATCTAATCC-3') and 520F (5'-AYTGGGYDTAAAGNG-3') were utilized for amplifying the V4 hypervariable regions of bacterial 16S rRNA gene, with a sample-specific 12 bp barcode added to 520F. The PCR reaction was conducted in the thermal cycler (Bio-Rad Laboratories, Hercules, CA, USA). Library quality was assessed by an Agilent Bioanalyzer 2100 and a Qubit 2.0 fluorometer. At last, high-throughput sequencing of $16 \mathrm{~S}$ rRNA genes was performed by Illumina MiSeq (Personalbio Technology Co. Ltd., Shanghai, China) and 300-bp paired-end reads were obtained. The data were submitted to the NCBI (number: PRJNA763332).

Read pairs from raw data were initially merged in FLASH version 1.2.7, in which forward and reverse reads had more than 10-bp overlaps and no base mismatches. Illumina sequence reads were processed by the quantitative insights into microbial ecology (QIIME) pipeline. In briefly, low-quality sequence reads were removed, and the 12-bp barcode was inspected to allocate the multiplexed reads to samples. Chimeric sequences were identified with the Uchime algorithm in a chimera-free reference database using the Usearch tool. The high-quality sequences with a $97 \%$ similarity were allocated to OTUs (operational taxonomic units) with Uclust clustering method. A representative sequence from each OTU was aligned with PyNAST against the GreenGene Database (v13_5). The taxonomic classification of OTUs was conducted with the RDP Classifier against the GreenGene Database (v13_5) with a percent similarity threshold of $97 \%$.

\subsection{Statistical analysis}

The soil organic $\mathrm{C}$ accumulation rate was computed as follows:

Accumulation rate $=$ (organic $\mathrm{C}$ content in $2009-$ organic C content in 1989)/20.

One-way analysis of variance was employed to assess the effects of long-term fertilization on soil properties. The least significant difference method was carried out using SPSS 18 for Windows (SPSS Inc., Chicago, IL, USA) to test statistically significant differences among treatments at the 5\% level. The relations between the soil microorganisms and soil properties as well as the effects of long-term fertilization on microbial community composition were evaluated using canonical correspondence analysis (CCA).

\section{Results}

\subsection{Soil properties}

The SOC and total $\mathrm{N}$ contents increased to a greater extent after 20-year compost application than inorganic fertilization (Table 2). The CM treatment had the highest accumulation rate of SOC $\left(0.39 \mathrm{~g} \mathrm{C} \mathrm{kg}^{-1} \cdot \mathrm{yr}^{-1}\right)$, followed by $\mathrm{HCM}\left(0.24 \mathrm{~g} \mathrm{C} \mathrm{kg}^{-1} \cdot \mathrm{yr}^{-1}\right)$, while the NK treatment presented the lowest accumulation rate of SOC $(0.04 \mathrm{~g} \mathrm{C}$ $\left.\mathrm{kg}^{-1} \cdot \mathrm{yr}^{-1}\right)$. The CM, HCM and NPK treatments also presented significantly greater soil carbohydrate content than the Control $(P<0.05)$, while the NK and PK application did not. The highest SCMR was $0.52 \mathrm{mg}$ $\mathrm{C} \cdot \mathrm{g}^{-1}$ SOC $\cdot \mathrm{day}^{-1}$ in the PK treated soil, while the lowest was in the CM treated soil $\left(0.32 \mathrm{mg} \mathrm{C} \cdot \mathrm{g}^{-1} \mathrm{SOC} \cdot \mathrm{day}^{-1}\right)$. Compost and inorganic $\mathrm{N}$ treatments decreased the soil pH significantly $(P<0.05)$. 
Table 2 Soil properties, organic $\mathrm{C}$ accumulation rate and SCMR in soil following 20 years of organic and inorganic fertilizer application.

\begin{tabular}{|c|c|c|c|c|c|c|c|}
\hline $\begin{array}{l}\text { Treat } \\
\text { ment }\end{array}$ & $\mathrm{pH}$ & $\begin{array}{c}\mathrm{SOC} \\
(\mathrm{g} \\
\left.\mathrm{C} \cdot \mathrm{kg}^{-1}\right)\end{array}$ & $\begin{array}{c}\text { Total } \\
\mathrm{N} \\
(\mathrm{g} \\
\mathrm{N} \cdot \mathrm{kg}^{-} \\
1)\end{array}$ & $\mathrm{C} / \mathrm{N}$ & $\begin{array}{c}\text { Carboh } \\
\text { ydrates } \\
(\mathrm{g} \\
\mathrm{C} \cdot \mathrm{kg}^{-1} \\
\text { soil })\end{array}$ & $\begin{array}{c}\text { SOC } \\
\text { accum } \\
\text { ulation } \\
\text { rate } \\
(\mathrm{g} \\
\mathrm{C} \cdot \mathrm{kg}^{-1} \\
\mathrm{soil}^{-1} \mathrm{yr}^{-} \\
1)\end{array}$ & $\begin{array}{c}\mathrm{SCMR} \\
\left(\mathrm{mg} \mathrm{C} \cdot \mathrm{g}^{-}\right. \\
{ }^{1} \mathrm{SOC} \cdot \mathrm{d}^{-} \\
\left.{ }^{1}\right)\end{array}$ \\
\hline $\begin{array}{c}\text { Contr } \\
\text { ol }\end{array}$ & $\begin{array}{c}8.39 \\
(0.02) \\
\mathrm{a}\end{array}$ & $\begin{array}{c}4.45 \\
(0.03) \mathrm{e}\end{array}$ & $\begin{array}{c}0.47 \\
(0.02) f\end{array}$ & $\begin{array}{c}9.47 \\
(0.34) \\
\text { a }\end{array}$ & $\begin{array}{c}0.49 \\
(0.04) \mathrm{e}\end{array}$ & $\begin{array}{c}0.00 \\
(0.00) \mathrm{f}\end{array}$ & $\begin{array}{c}0.34 \\
(0.01 \\
) \mathrm{c}\end{array}$ \\
\hline $\mathrm{CM}$ & $\begin{array}{c}8.06 \\
(0.06) \\
\mathrm{c}\end{array}$ & $\begin{array}{c}12.20 \\
(0.08) \mathrm{a}\end{array}$ & $\begin{array}{c}1.56 \\
(0.03) \\
\mathrm{a}\end{array}$ & $\begin{array}{c}7.82 \\
(0.10) \\
\mathrm{c}\end{array}$ & $\begin{array}{c}1.00 \\
(0.04) \mathrm{a}\end{array}$ & $\begin{array}{c}0.39 \\
(0.00) \mathrm{a}\end{array}$ & $\begin{array}{c}0.32 \\
(0.02 \\
) \mathrm{c}\end{array}$ \\
\hline $\mathrm{HCM}$ & $\begin{array}{c}7.90 \\
(0.01) \\
\mathrm{d}\end{array}$ & $\begin{array}{c}9.28 \\
(0.08) b\end{array}$ & $\begin{array}{c}1.10 \\
(0.03) \\
\mathrm{b}\end{array}$ & $\begin{array}{c}8.44 \\
(0.19) \\
\text { b }\end{array}$ & $\begin{array}{c}0.78 \\
(0.06) b\end{array}$ & $\begin{array}{c}0.24 \\
(0.01) b\end{array}$ & $\begin{array}{c}0.41 \\
(0.00 \\
) \mathrm{b}\end{array}$ \\
\hline NPK & $\begin{array}{c}8.00 \\
(0.05) \\
\mathrm{c}\end{array}$ & $\begin{array}{c}7.00 \\
(0.04) \mathrm{c}\end{array}$ & $\begin{array}{c}0.80 \\
(0.03) \\
\mathrm{c}\end{array}$ & $\begin{array}{c}8.75 \\
(0.23) \\
\mathrm{b}\end{array}$ & $\begin{array}{c}0.60 \\
(0.02) \mathrm{c}\end{array}$ & $\begin{array}{c}0.13 \\
(0.01) \mathrm{c}\end{array}$ & $\begin{array}{c}0.43 \\
(0.02 \\
) \mathrm{b}\end{array}$ \\
\hline NP & $\begin{array}{c}8.24 \\
(0.00) \\
\mathrm{b}\end{array}$ & $\begin{array}{c}6.64 \\
(0.05) \mathrm{c}\end{array}$ & $\begin{array}{c}0.76 \\
(0.02) \\
\mathrm{d}\end{array}$ & $\begin{array}{c}8.74 \\
(0.15) \\
\text { b }\end{array}$ & $\begin{array}{c}0.58 \\
(0.04) \mathrm{d}\end{array}$ & $\begin{array}{c}0.11 \\
(0.01) \mathrm{c}\end{array}$ & $\begin{array}{c}0.38 \\
(0.00 \\
) \mathrm{bc}\end{array}$ \\
\hline NK & $\begin{array}{c}8.03 \\
(0.09) \\
\mathrm{c}\end{array}$ & $\begin{array}{c}5.22 \\
(0.06) \mathrm{d} \\
\mathrm{e}\end{array}$ & $\begin{array}{c}0.88 \\
(0.02) \\
\mathrm{c}\end{array}$ & $\begin{array}{c}5.93 \\
(0.07) \\
\mathrm{a}\end{array}$ & $\begin{array}{c}0.55 \\
(0.03) \mathrm{e}\end{array}$ & $\begin{array}{c}0.04 \\
(0.00) \mathrm{e}\end{array}$ & $\begin{array}{c}0.32 \\
(0.02 \\
) \mathrm{c}\end{array}$ \\
\hline PK & $\begin{array}{c}8.34 \\
(0.01) \\
\mathrm{a} \\
\end{array}$ & $\begin{array}{c}5.80 \\
(0.10) \mathrm{d}\end{array}$ & $\begin{array}{c}0.62 \\
(0.01) \\
\mathrm{e}\end{array}$ & $\begin{array}{c}9.35 \\
(0.01) \\
\mathrm{d} \\
\end{array}$ & $\begin{array}{c}0.51 \\
(0.04) \mathrm{e}\end{array}$ & $\begin{array}{c}0.07 \\
(0.00) \mathrm{d}\end{array}$ & $\begin{array}{c}0.52 \\
(0.05 \\
) \mathrm{a} \\
\end{array}$ \\
\hline
\end{tabular}

The standard deviations (sd) are shown in parentheses $(n=4)$. Different letters represent significant differences between treatments at $P<0.05$.

The Control treatment had significantly greater D (5.19 $\times 10^{-6} \mathrm{~m}^{2} \cdot \mathrm{s}^{-1}$, Fig. 1$)$ than the other treatments $(P<0.05)$, while the $\mathrm{CM}$ treatment had the lowest vaule $(1.30 \times$ $\left.10^{-6} \mathrm{~m}^{2} \cdot \mathrm{s}^{-1}\right)$. The D significantly differed among treatments $(P<0.05)$ and were in the order of $\mathrm{CM}<$ $\mathrm{HCM}<\mathrm{PK}$, NP and NPK $<$ NK $<$ Control.

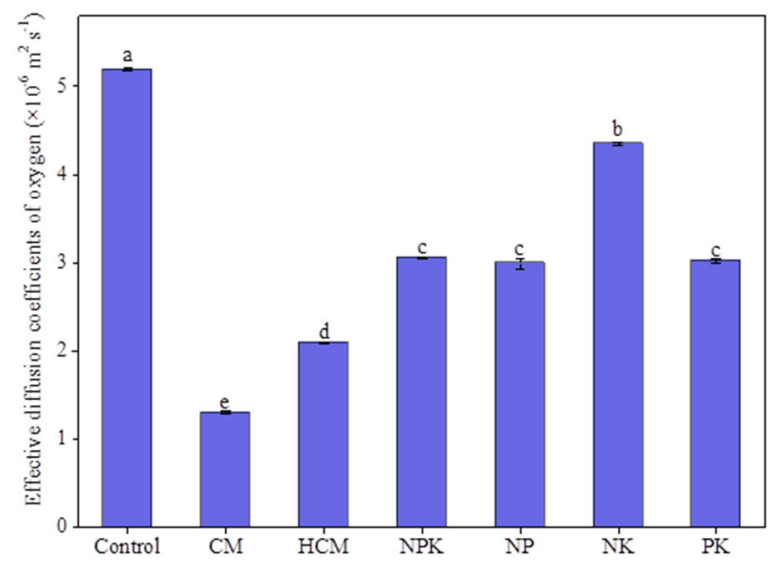

Fig. 1 The effective diffusion coefficient of oxygen (D) in different long-term (20 years) fertilization treatments. Vertical bars indicate the sd $(\mathrm{n}=4)$. Different letters represent significant differences between treatments at $P<0.05$.

\subsection{Bacterial community composition}

The 16S rRNA Illumina sequencing generated 517,660 high-quality sequences in total, with 73,951 sequences and 8372 unique OTUs per sample on average (OTUs are defined as sequences with $97 \%$ similarity), and the average read length was $225 \mathrm{bp}$. Eleven phylum-level groups were selected for the statistical analysis (Fig. 2). Of these, the most predominant phylum was Proteobacteria in all treatments, and accounted for $25.4-32.7 \%$ of the total abundance. Actinobacteria, Bacteroidetes, and Acidobacteria also constituted a large proportion of the total microbial abundance in all treatments and accounted for $17.1-21.4 \%, 8.4-23.4 \%$, and $9.2-16.2 \%$ of the total abundance, respectively. Fertilization treatments presented lower relative abundance (RA) of Bacteroidetes and higher Proteobacteria and Verrucomicrobia than the Control. The RA of Firmicutes was augmented by $90.47 \%$ and $68.32 \%$, respectively in the CM and HCM treatments but reduced by $52.47 \%-78.18 \%$ in the inorganic fertilization treatments. Relative to the Control treatment, the change of the RA of Firmicutes was mainly due to the variation in Bacillales in fertilizer-treated soil (Fig. 3). Nonetheless, the RA of Acidobacteria decreased slightly in the compost treatments (CM and HCM) but increased by $49.0 \%$ under NPK treatment and by $11.8-13.1 \%$ under unbalanced fertilization treatments relative to the Control.

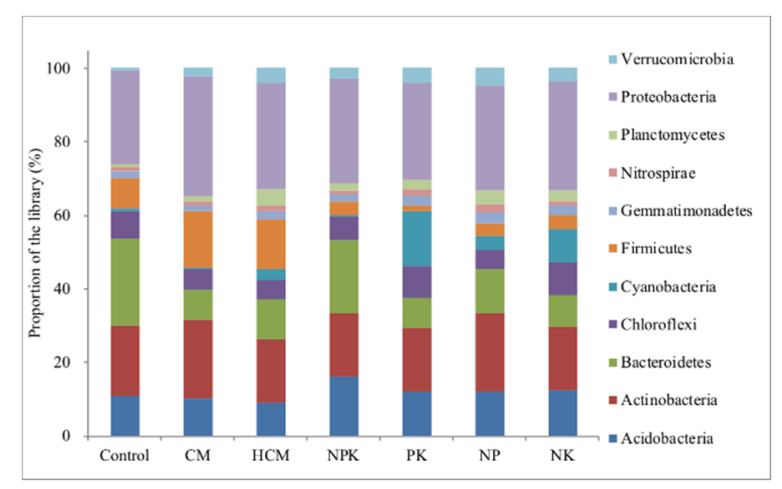

Fig. 2 Relative abundance (RA) of bacteria phyla in different long-term (20 years) fertilization treatments.

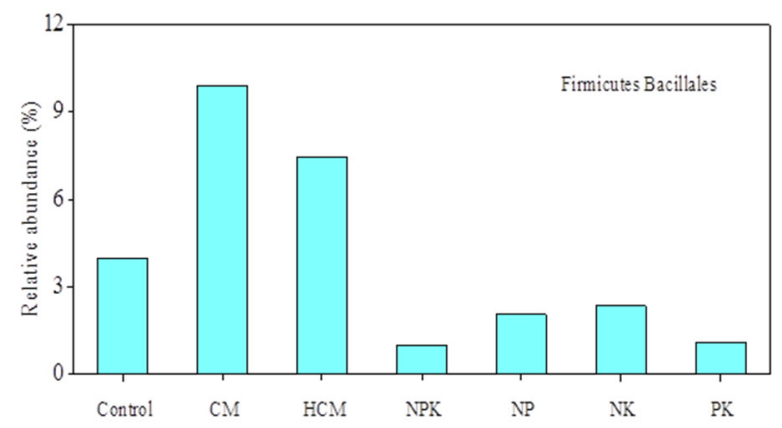

Fig. 3 Relative abundance (RA) of order Bacillales within phylum Firmicutes in different long-term (20 years) fertilization treatments.

For classes within phylum Proteobacteria, Alphaproteobacteria augmented in the NPK and CM treatments relative to the Control (Fig. 4). The RA of Beta-proteobacteria augmented in all fertilization treatments except NPK. The RA of Gammaproteobacteria augmented in the $\mathrm{CM}$ treatment while 
reduced in the other treatments. On the contrary, the RA of Delta-proteobacteria remained relatively stable in the CM treatment, but increased by $46.87 \%-74.33 \%$ in the other treatments. Finer taxonomic divisions revealed that the CM treatment presented the greatest RA of the order Xanthomonadales within Gamma-proteobacteria (Fig. 5).
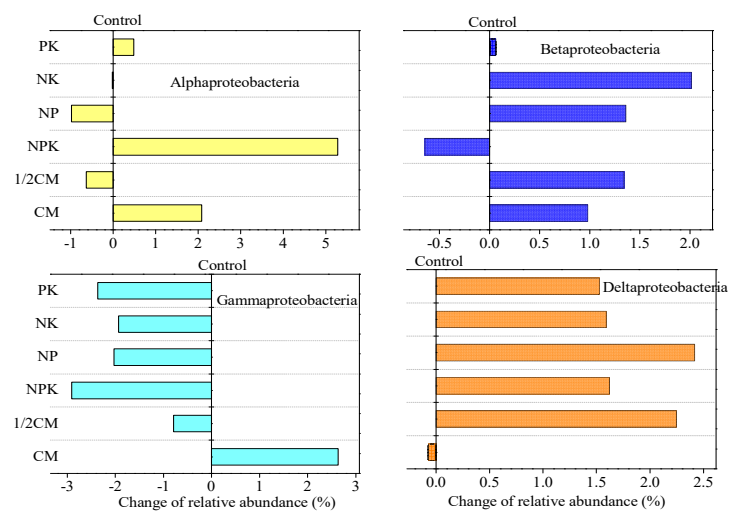

Fig. 4 Changes in the relative abundance (RA) of four classes of Proteobacteria (Alpha-proteobacteria, Beta-proteobacteria, Gamma-proteobacteria, and Delta-proteobacteria) in soil treated with compost and inorganic fertilizer application for 20 years compared with the Control.

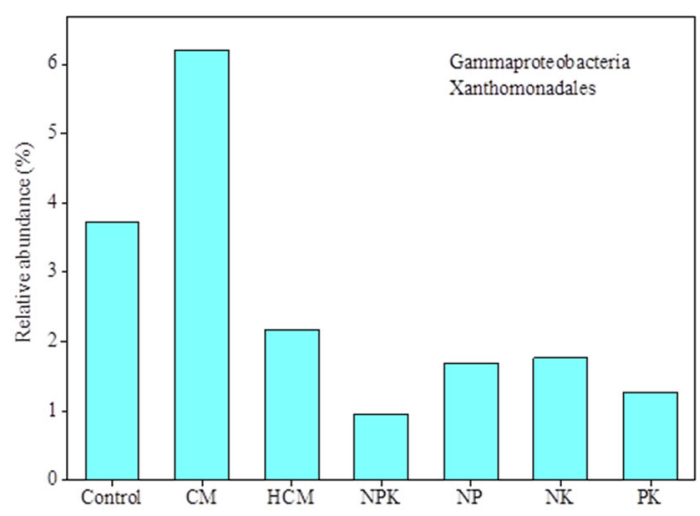

Fig. 5 Relative abundance (RA) of order Xanthomonadales within Gamma-proteobacteria in different long-term (20 years) fertilization treatments.

\subsection{Relations between soil properties and microbial taxa}

The SOC, SOC accumulation rate, carbohydrate content, and the total $\mathrm{N}$ were significantly $(P<0.05)$ correlated with the RA of Firmicutes and Proteobacteria (Fig. 6). The CCA ordination plots showed that the D was significantly $(P<0.05)$ related with the SOC, carbohydrate content, and SOC accumulation rate (Fig. 7). OTUs identified as Mogibacterium in the Clostridiales order, Bacillus asahii in the Bacillales order, and Xanthomonadaceae in the Xanthomonadales order were significantly related with the SOC accumulation rate, SOC, and carbohydrate content $(P<$ $0.05)$, but a negative correlation was observed between the D and the above OTUs.
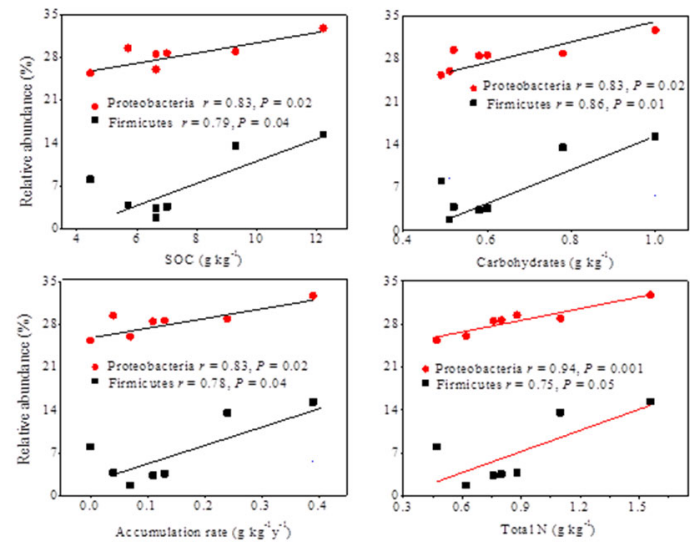

Fig. 6 Relation between the relative abundance (RA) of two bacterial groups, SOC, carbohydrate content, total $\mathrm{N}$ content, and organic $\mathrm{C}$ accumulation rate in different long-term (20 years) fertilization treatments.

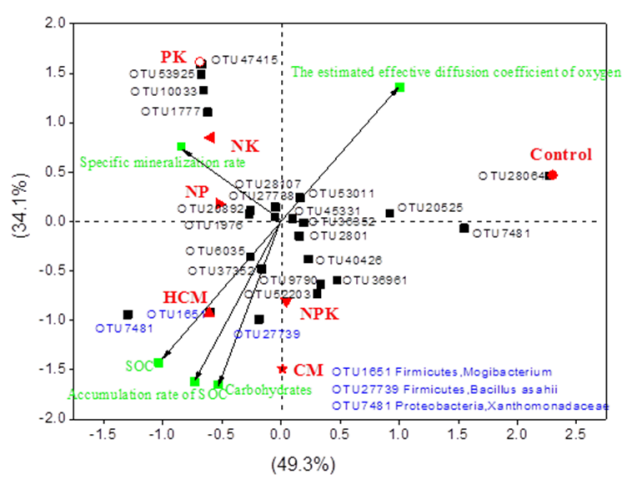

Fig. 7 Canonical correspondence analysis (CCA) illustrating the relation between microorganisms and some soil properties such as SOC, carbohydrate, accumulation rate of organic C, specific mineralization rate of organic $\mathrm{C}$, and the effective oxygen diffusion coefficient at the OTU level.

\section{Discussion}

Proteobacteria and Bacteroidetes are generally considered to be copiotrophic taxa which likely flourish in soils as the availability of SOC increases. Our result showed that long-term fertilization enhanced the RA of Proteobacteria but reduced that of Bacteroidetes in soil relative to the Control (Fig. 2). However, an analysis of the finer taxonomic divisions revealed that the RA of order Xanthomonadales within Gammaproteobacteria increased only in the CM-treated soils, where the SOC $\left(12.20 \mathrm{~g} \mathrm{C} \cdot \mathrm{kg}^{-1}\right)$ was greater than the other treatments (Fig. 5). Similarly, in previous studies, Xanthomonadales were reported to be more plentiful in long-term $\mathrm{N}$ fertilized treatment than the Control or unfertilized treatment when the SOC content was grerater than $12 \mathrm{~g}$ $\mathrm{C} \cdot \mathrm{kg}^{-1}$ [1]. More importantly, Li et al. [10] reported that the RA of Xanthomonadales increased with decreasing oxygen content of soil. Thus, we speculated that the SOC, particularly the effective oxygen diffusion coefficient, determined the growth of Xanthomonadales in our study. Our result showed that the Control 
treatment presented the highest abundance of Bacteroidetes. Similar to our findings, Li et al. [10] and Zeng et al. [2] also revealed that the abundance of Bacteroidetes decreased in soils treated with fertilizer (inorganic fertilizer combined with wheat straw or inorganic fertilizer alone). This may be because Bacteroidetes were not only positively correlated to availability of $\mathrm{C}$ or $\mathrm{N}$ but also negatively correlated with soil $\mathrm{pH}$.

In contrast to Bacteroidetes and Proteobacteria, Acidobacteria can grow at low $\mathrm{pH}$ and utilize nutrientpoor and recalcitrant $\mathrm{C}$ substrates. In our study, Acidobacteria had the greatest RA in the NPK treatment, probably due to its relatively low $\mathrm{pH}$. Although the HCM treatment presented lower $\mathrm{pH}$ than the NPK treatment, it had a higher SOC, consequently inhibiting the growth of Acidobacteria as members of this phylum favor oligotrophic conditions. In current study, the RA of Firmicutes, especially Bacillus spp., augmented by compost application but decreased following inorganic fertilizer treatment, which is in consistent with the results of the previous study [10]. Feng et al. [11] found that compost application not only increased the abundance of Bacilli significantly but also changed its composition, while NPK did not. It is likely that the soil environment established in the compost-treated soil provided a more suitable niche for the growth of indigenous Bacillus spp. [11].

We found that the RA of Firmicutes and Proteobacteria was significantly related with the SOC, carbohydrate content, and SOC accumulation rate (Fig. 6), in accordance with the results reported in previous studies. A major part of the identified anaerobic respiration genes have been allocated to the Firmicutes, Proteobacteria, and Actinobacteria phyla, which decomposed SOC at lower rates under anaerobic conditions than under aerobic conditions. In the present study, fertilization treatments, especially compost application, decreased the effective oxygen diffusion coefficient due to the changes in the pore systems and enhanced the RA of Proteobacteria and Firmicutes. Our results suggest that there was a gradual transition of SOC degradation from aerobic to anaerobic with increasing SOC [11]. In addition, Actinobacteria, Bacteroidetes, and Verrucomicrobia accounted for $>70 \%$ of genes that were allocated to the three main groups of polysaccharide degradation (cellulases, endohemicellulases, and debranching enzymes). Thus, the significant decline in the abundance of Bacteroidetes in fertilized soils may have favored polysaccharide accumulation.

For finer divisions, we found that the Mogibacterium, Bacillus and Xanthomonadaceae showed positive correlations with the accumulation rate of SOC (Fig. 7). Previous researches have illustrated that the increase in the abundance of Bacillus significantly improved the activities of both lipase and polyphenol oxidase in soil, and then promoted soil organic matter to be transformed into humus, which is the main component of SOC. Thus far, however, how Mogibacterium and the Xanthomonadaceae family favor organic $\mathrm{C}$ accumulation remains to be understood and the function of these bacteria requires to be elucidated in future studies.

\section{Conclusion}

In conclusion, 20-year compost application was more favorable in augmenting the SOC content compared with inorganic fertilizer application. However, the Control treatment presented significantly greater $\mathrm{D}$ than the other treatments, especially in compost-treated soils. The soil bacterial community structure was altered by the shifts in soil properties between fertilization treatments. Fertilizer application decreased the RA of Bacteroidetes but augmented the RA of Proteobacteria. Compost application increased the RA of Firmicutes but inorganic fertilizer application decreased it. The enhancement of the RA of Proteobacteria and Firmicutes indicated degradation of SOC was gradually shrifted from aerobic to anaerobic with the application of fertilizers, especially in compost treatment, which would favor SOC accumulation. However, the significant reduction of the RA of Bacteroidetes in fertilized soils may have favored polysaccharide accumulation. At the genus levels, the RA of Bacillus spp. was higher in compost-treated soils, which could improve the conversion of soil organic matter into humus. This study aids in clarifying the impact of long-term organic and inorganic fertilization on bacterial community and its relation to organic carbon accumulation in a sandy loam soil.

\section{References}

1. K. Jangid, M.A. Williams, A.J. Franzluebbers, J.S. Sanderlin, J.H. Reeves, M.B. Jenkins, D.M. Endale, D.C. Coleman, W.B. Whitman, Relative impacts of land-use, management intensity and fertilization upon soil microbial community structure in agricultural systems, Soil Biol Biochem, 40 (2008) 2843-2853.

2. J. Zeng, X.J. Liu, L. Song, X.G. Lin, H.Y. Zhang, C.C. Shen, H.Y. Chu, Nitrogen fertilization directly affects soil bacterial diversity and indirectly affects bacterial community composition, Soil Biol Biochem, 92 (2016) 41-49.

3. Y. Ge, J.B. Zhang, L.M. Zhang, M. Yang, J.Z. He, Long-term Fertilization Regimes Affect Bacterial Community Structure and Diversity of an Agricultural Soil in Northern China, Journal of Soils and Sediments, 8 (2008) 43-50.

4. K.S. Ramirez, J.M. Craine, N. Fierer, Consistent effects of nitrogen amendments on soil microbial communities and processes across biomes, Global Change Biology, 18 (2012) 1918-1927.

5. M. Sapp, M. Harrison, U. Hany, A. Charlton, R. Thwaites, Comparing the effect of digestate and chemical fertiliser on soil bacteria, Applied Soil Ecology, 86 (2015) 1-9.

6. K.S. Ramirez, J.M. Craine, N. Fierer, Nitrogen fertilization inhibits soil microbial respiration 
regardless of the form of nitrogen applied, Soil Biol Biochem, 42 (2010) 2336-2338.

7. H.Y. Yu, W.X. Ding, J.F. Luo, R.L. Geng, A. Ghani, Z.C. Cai, Effects of long-term compost and fertilizer application on stability of aggregate-associated organic carbon in an intensively cultivated sandy loam soil, Biology and Fertility of Soils, 48 (2012) 325-336.

8. P. Puget, D.A. Angers, C. Chenu, Nature of carbohydrates associated with water-stable aggregates of two cultivated soils, Soil Biol Biochem, 31 (1999) 55-63.

9. M. Aachib, M. Mbonimpa, M. Aubertin, Measurement and prediction of the oxygen diffusion coefficient in unsaturated media, with applications to soil covers, Water Air Soil Pollut., 156 (2004) 163-193.

10. C.H. Li, K. Yan, L.S. Tang, Z.J. Jia, Y. Li, Change in deep soil microbial communities due to long-term fertilization, Soil Biol Biochem, 75 (2014) 264-272.

11. Y.Z. Feng, R.R. Chen, J.L. Hu, F. Zhao, J.H. Wang, H.Y. Chu, J.B. Zhang, J. Dolfing, X.G. Lin, Bacillus asahii comes to the fore in organic manure fertilized alkaline soils, Soil Biol Biochem, 81 (2015) 186194. 